\title{
PENINGKATAN TATA KELOLA MAJALAH SEKOLAH SMAK IPEKA TOMANG
}

\author{
Anny Valentina ${ }^{1}$, Ruby Chrissandy ${ }^{2}$ \\ ${ }^{1,2}$ Fakultas Seni Rupa dan Desain, Universitas Tarumanagara Jakarta \\ Program Studi Desain Komunikasi Visual \\ Surel: annyv@ fsrd.untar.ac.id com ${ }^{1}$, rubyc@ @fsrd.untar.ac.id ${ }^{2}$
}

\begin{abstract}
This a continuation community service activity to develop and manage the publication of the IPEKA SMA magazine (KEPO e-Magazine). Magazine as one of the traditional communication media that still become one of a preferable communication medium. Magazines derive from the specialization of their contents can be divided into several categories, one of which is school magazines. This activity also support magazine as a school communication medium and fulfill the School Literacy Movement (GLS) program through appropriate communication methods and are of interest to readers. After coaching with some materials of magazine management, structure, design, publication, editorial and marketing will follow by review and evaluation that held on for the newly formed Magazine Editorial Team. This activity tries to find out more information of any improvement and difficulties faced by the Editorial Team in between producing the e-magazine. This activity involves the ArtMAX magazine team, a magazine published by FSRD UNTAR, and will be carried out in 3 stages (online training, review, and evaluation). In addition, it is also necessary to conduct a review and evaluation of the readers of the e-magazine, to find out more about the readers' views on all the elements of the e-magazine that have been published. As a result, many improvements can be made and so that delivering information process can be conveyed with attractive visuals.
\end{abstract}

Keywords: Magazine, Communication Media, E-magazine, Visual

\section{ABSTRAK}

Kegiatan pengabdian ini merupakan kegiatan lanjutan dari kegiatan pengabdian pembinaan dan tata kelola penerbitan majalah SMA IPEKA yang diberi nama KEPO e-Magazine. Majalah sebagai salah satu media komunikasi tradisional yang hingga saat ini masih menjadi media komunikasi yang dipilih. Majalah dilihat dari pengkhususan isinya bisa dibedakan atas beberapa kategori, salah satunya adalah Majalah sekolah. Kegiatan ini juga mendukung upaya Membangun Majalah Sebagai Media Komunikasi Sekolah dan memenuhi program Gerakan Literasi Sekolah (GLS) melalui cara komunikasi yang sesuai dan diminati oleh pembaca. Setelah dilakukan pembinaan dengan materi berupa tata kelola majalah, struktural, desain, publikasi, editorial dan marketing, pada tahap selanjutnya, diadakan review dan evaluasi secara keseluruhan dari Tim Redaksi Majalah yang baru dibentuk. Guna mencari tahu lebih lanjut jika ada kesulitan yang dihadapi oleh Tim Redaksi saat memproduksi e-magazine tersebut. Kegiatan ini melibatkan tim majalah ArtMAX, majalah yang diterbitkan oleh FSRD UNTAR dan akan dilakukan dalam 3 tahap (pelatihan daring, review dan evaluasi). Selain itu, juga perlu diadakan review dan evaluasi kepada para pembaca e-magazine, guna mencari tahu lebih lanjut pandangan pembaca terhadap semua unsur $e$ magazine yang sudah diterbitkan. Hasil dari review dan evaluasi ini dapat dijadikan landasan untuk melakukan perbaikan dan juga peningkatan hasil majalah ke depannya. Sehingga penyampaian informasi bisa tersampaikan dengan lebih baik dengan visual yang menarik.

Kata kunci: Majalah, Media Komunikasi, E-magazine, Visual

\section{PENDAHULUAN}

\section{Analisis situasi}

Sebagai salah satu media komunikasi tradisional, majalah hingga saat ini masih menjadi media komunikasi yang dipilih. Majalah sendiri diakses dari situs https://kbbi.web.id/majalah adalah terbitan berkala yang isinya meliputi berbagai liputan jurnalistik, pandangan tentang topik aktual yang patut diketahui pembaca, dan menurut waktu penerbitannya dibedakan atas majalah bulanan, tengah bulanan, mingguan, dan sebagainya dan menurut pengkhususan isinya dibedakan atas majalah berita, wanita, remaja, olahraga, sastra, ilmu pengetahuan tertentu, dan sebagainya. 
Salah satu jenis majalah yang hingga saat ini masih berjalan adalah majalah sekolah. Sebagai majalah yang diterbitkan dan dikelola oleh sekolah, keberadaan majalah menjadi sangat penting sebagai media untuk menampung kegiatan dan karya siswa sekaligus media komunikasi. Menurut Arfiani (2013) majalah sekolah memiliki sifat yang informatif, edukatif, sekaligus rekreatif. Dengan sifat tersebut majalah sejatinya bisa dimanfaatkan juga sebagai media pembelajaran. Sebagai bagian dari media cetak, majalah memiliki kelebihan seperti dapat dinikmati dalam waktu yamg lama dengan pembaca yang lebih spesifik, dan memiliki kualitas visual yang baik. Karena pembacanya yang spesifik, majalah bisa menjangkau kelas tertentu atau golongan tertentu. Majalah sendiri memiliki karakter yang lebih prestige dan lebih mudah diterima. Di sisi lainnya ada kekurangan majalah seperti biaya cetaknya yang cukup tinggi, dan masalah distribusi yang cukup rumit. Diyanti, Wendra, dan Tantri (2021) menyatakan bahwa majalah sekolah adalah media cetak yang diterbitkan secara berkala oleh sekolah dengan format konvensional dalam sebuah majalah dan sasarannya orang-orang yang berkepentingan dengan sekolah. Isi majalah sekolah biasanya memiliki kaitan dengan kepentingan komunikasi pendidikan serta pengajaran di sekolah. Selain itu manfaat penting majalah sekolah adalah sebagai sarana ekspresi peserta didik dalam menuangkan kreativitas menulis seperti cerpen, pantun, puisi, dan berita.

Majalah sekolah biasanya dikelola oleh pihak sekolah melalui kegiatan ekstra kurikuler jurnalistik. Kegiatan ekstra kurikuler ini memiliki manfaat: 1. Sebagai media penyaluran bakat siswa dalam bidang penulisan; 2 . Penyaluran minat dalam bidang yang sama; 3 . Membantu anak memahami dan mempraktikkan teori-teori dalam pelajaran bahasa; dan 4. Melatih anak tampil lebih berani dan kritis terhadap berbagai kondisi. Adapun manfaat dari majalah sekolah pun sangat besar. menyatakan bahwa manfaat majalah sekolah meliputi: 1. Sebagai media penyalur potensi menulis; 2. Sebagai penyalur aspirasi; 3. Sebagai media komunikasi; 4. Sebagai media pembelajaran berbasis baca-tulis; 5. Sebagai media belajar organisasi; 6. Sebagai penyemai demokrasi; 7. Sebagai media promosi (Utami, 2011).

Pada kegiatan pengabdian sebelumnya telah dipetakan bahwa pembuatan majalah sekolah sebagai salah satu bentuk kegiatan sekolah untuk mendukung program Gerakan Literasi Sekolah yang tercantum dalam Peraturan Mentri Pendidikan dan Kebudayaan nomor 23 tahun 2015. Dalam peraturan ini gerakan literasi sekolah dilaksanakan supaya siswa dapat menumbuhkan budi pekerti luhur. Bagian dari gerakan ini yaitu membaca buku nonpelajaran 15 menit sebelum memulai belajar. Kegiatan ini dilaksanakan untuk menumbuhkan dan meningkatkan minat baca siswa, bahan bacaan yang diberikan pada siswapun yang berisi untuk menumbuhkan budi pekerti, kearifan lokal, nasional, maupun global sesuai dengan tahap perkembangan siswa. Nurasiah (2017) menyatakan bahwa Program Gerakan Literasi sekolah membutuhkan adanya pengelolaan yang baik agar program GLS ini berjalan dengan semestinya.

\section{Permasalahan dan solusi}

Valentina, Anny dan Chrissandy, Ruby (2021) menyatakan bahwa pada kegiatan tahap pertama telah berhasil membentuk Tim Redaksi Majalah SMA IPEKA TOMANG, Jakarta Barat, dengan kepala sekolah sebagai pelindung; 4 orang guru pembina, seorang pemimpin redaksi. Tim Redaksi Majalah langsung dibentuk 4 tim untuk 4 edisi. Tiap tim akan diketuai oleh 1 redaktur pelaksana, beranggotakan: 1 editor, 2 reporter dan 2 desainer. Serta dilakukan pembekalan berupa seminar online tentang desain yang berisi pengetahuan dasar tentang tata letak dari desain dan landasan dasar mendesain. Seperti layout menurut Rustan (2014) dan warna menurut Sutherland (2004). Selain desain juga dilakukan pembekalan melalui seminar online tentang publikasi, editorial dan marketing. 


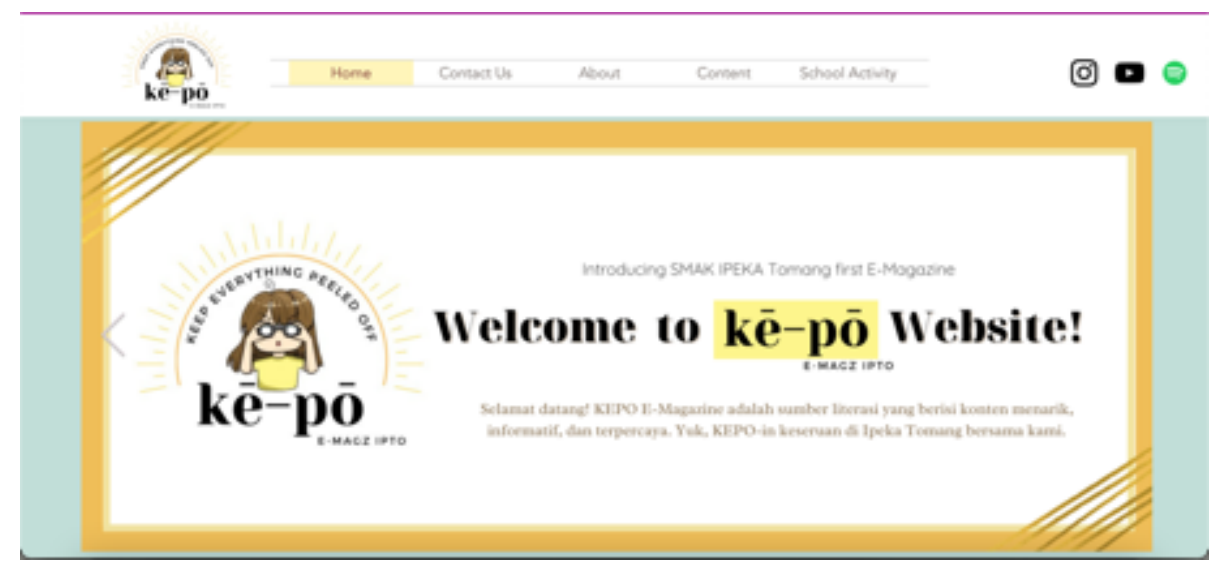

Gambar 1.Tampilan homepage website KEPO e-magazine

Setelah dilakukan pelatihan dan pengarahan dari Tim PKM Untar kepada SMA IPEKA Tomang, terbitlah majalah elektronik eksklusif untuk SMA IPEKA Tomang. Majalah elektronik atau yang biasa disebut e-magazine dapat diakses melalui website emagzipto.wixsite.com. Tim Redaksi dari SMA IPEKA Tomang berhasil menterjemahkan informasi seputar sekolah ke dalam format e-magazine dan mengemasnya dengan unik dan menarik, dilihat dari adanya beberapa fitur hiburan yang ada di dalam e-magazine; music playlist.

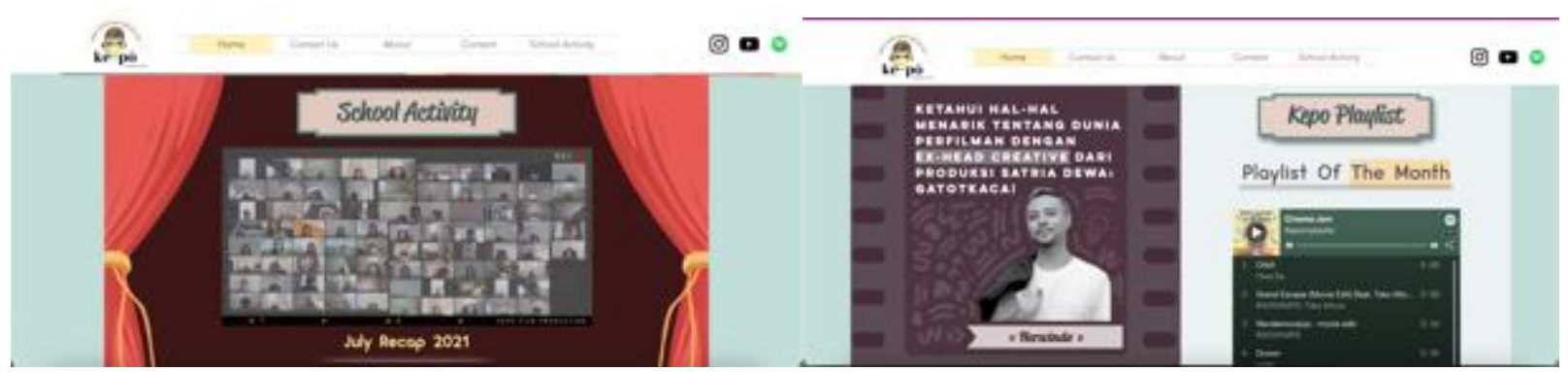

Gambar 2. Tampilan konten e-magazine SMA IPEKA TOMANG

Melalui pembuatan e-magazine ini, diharapkan minat baca murid maupun semua pihak yang tertarik dengan informasi seputar SMA IPEKA Tomang dapat lebih mudah dan lebih jelas tersampaikan. Untuk itu, perlu diadakannya review dan evaluasi lanjutan terhadap e-magazine yang sudah diterbitkan untuk mendapatkan data, pembelajaran, dan juga hal yang dapat ditingkatkan untuk menjadi lebih baik lagi pada penerbitan e-magazine selanjutnya. Untuk tahap selanjutnya, juga perlu diadakan review dan evaluasi mengenai cara kerja Tim Redaksi Majalah yang baru dibentuk. Guna mencari tahu lebih lanjut jika ada kesulitan yang dihadapi oleh Tim Redaksi saat memproduksi e-magazine tersebut. Selain itu, juga perlu diadakan review dan evaluasi kepada para pembaca e-magazine, guna mencari tahu lebih lanjut pandangan pembaca terhadap semua unsur e-magazine yang sudah diterbitkan. Sehingga ke depannya, dapat dilakukan perbaikan dan juga peningkatan sehingga proses penyampaian informasi bisa tersampaikan dengan lebih baik dan menarik. 


\section{METODE PELAKSANAAN PKM}

Pelaksanaan kegiatan ini melibatkan 3 mahasiswa yang memiliki pengalaman dalam pengelolaan majalah ArtMAX FSRD UNTAR pada pelaksanaan pelatihan. Metode pelaksanaan PKM ini akan dilakukan dalam waktu 12 bulan ( 2 semester) dimana pelaksanaan sudah berjalan selama 1 semester, dalam kegiatan ini akan berlangsung:

1. Tahap persiapan: (Sudah dilaksanakan)

- Menghubungi pihak sekolah SMAK IPEKA Tomang guna mengajak berdiskusi dan sharing tentang permasalahan yang dihadapi.

- Mengajukan permohonan untuk mengadakan kegiatan pelatihan.

- Melakukan persiapan dan penyusunan materi pelatihan sambil menunggu jadwal yang diberikan oleh mitra.

\section{Tahap Pelaksanaan PKM}

Tahap Pelaksanakan PKM akan dibagi menjadi 3 tahap, dimana tahap 1 yaitu :

- Tim FSRD Melaksanaan pelatihan tahap pertama sesuai dengan jadwal yang diberikan yaitu pada hari Senin, 5 April 2021 pada pukul 14.00 - sampai selesai

- Pelatihan tahap pertama ini menggunakan metode workshop secara daring dengan menggunakan Google Meet yang telah disiapkan oleh pihak sekolah dan telah selesai dilaksanakan.

Pelaksanaan PKM tahap 2 dan 3 berupa :

- Tim FSRD dibantu Tim KEPO e-magazine melaksanaan review melalui Google Form sesuai dengan jadwal menyusul (bulan Juni-Juli 2021). Sebagai lahapan lanjutan untuk melihat hasil dari pelatihan yang dilaksanakan.

- Tim FSRD Melaksanaan evaluasi pada tanggal 12 Agustus 2021, melalui Google Meet yang telah disiapkan oleh pihak sekolah sebagai tahap lanjutan untuk melihat hasil review dari majalah sekolah yang dibuat.

3. Tahap luaran dari PKM ini berupa mengikuti temu ilmiah serta pendaftaran HKI yang telah dibuat.

\section{Tahap 1 (telah dilaksanakan)}

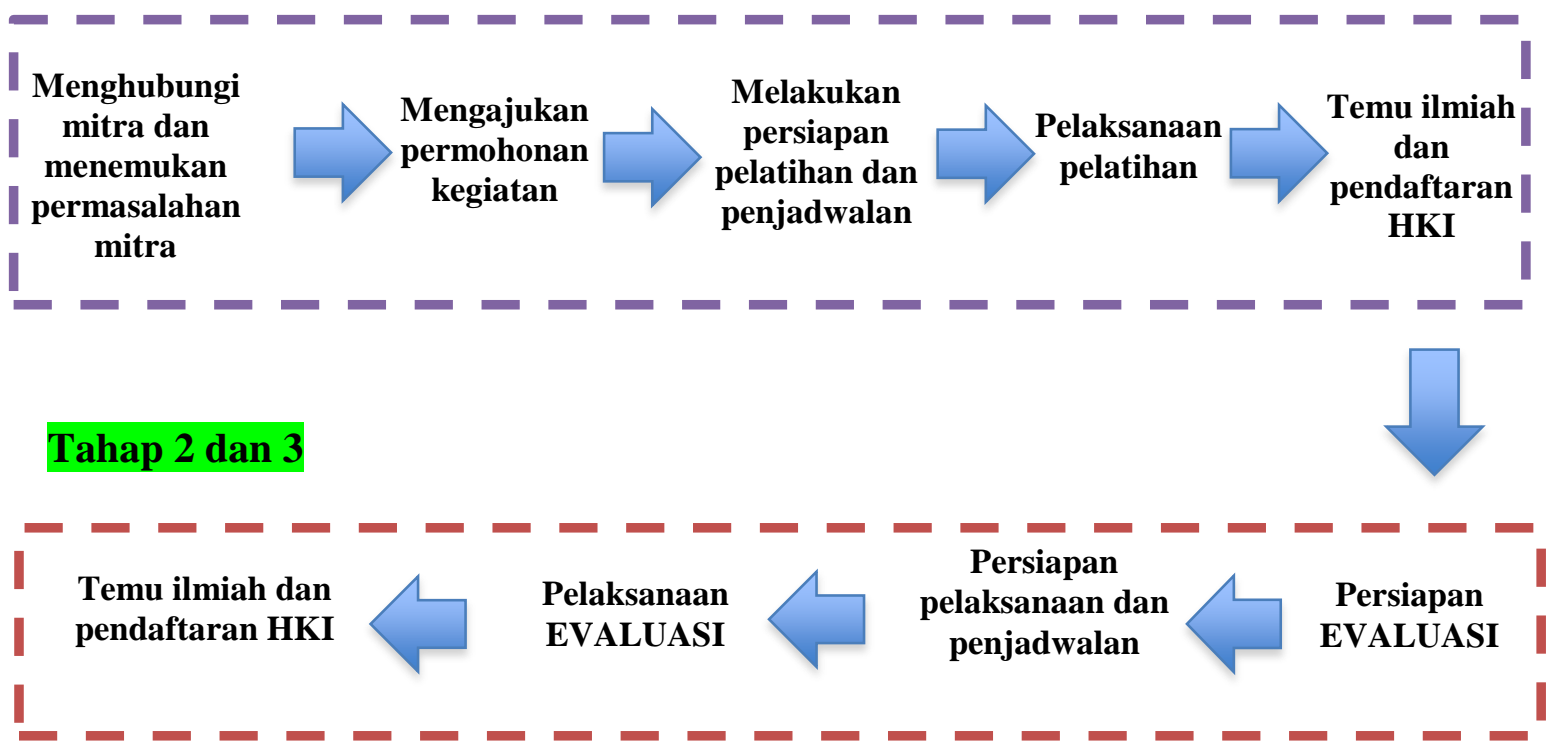




\section{HASIL DAN PEMBAHASAN}

Melalui pertemuan secara daring dengan tim KEPO e-magazine, ada asumsi sementara dari tim bahwa peminat baca majalah tidak terlalu banyak, karena dilihat dari peminat pembaca koran dan berita harian yang terus berkurang, karena itu tim KEPO e-magazine mencoba membuat strategi bagaimana agar orang bisa tertarik untuk membaca e-magz, tidak hanya dengan memberikan informasi tapi mencari cara pengemasan yang semenarik mungkin. Tim KEPO $e$ magazine mencoba memberikan ide berupa membuat artikel berupa recap aktivitas sekolah secara bulanan selain itu juga memberikan playlist bulanan.

Tema edisi 1: Perkuliahan, tema ini dipilih dengan pertimbangan target dari e-magazine adalah anak-anak SMA, karena itu dipandang bisa menjawab kebutuhan anak SMA yang masih bingung tentang perkuliahan. e-magazine ini diharapkan memberikan dampak yang bagus bagi siswa siswi SMA.

Konten:

- Jurusan

- Tips memilih PTS/PTN

- Wawancara dengan alumni; Brian Winstontly, alumni SMAK IPEKA Tomang

Referensi:

- e-magz untar

- e-magz sekolah lain

Setelah KEPO e-magazine pertama terbit, dilakukan survey secara daring melalui gform, hal ini dilakukan guna mengetahui pendapat pembaca mengenai e-magazine tentang edisi pertama ini. Selain itu respon ini sangat penting didapatkan untuk tim redaksi bisa melakukan perbaikan dalam persiapan konten dan hal-hal yang lebih menarik lagi untuk edisi selanjutnya.

Responden hampir seluruhnya telah mengakses KEPO e-magazine, dan 63,4\% nya beranggapan tampilan layout dari website KEPO e-magazine sangat menarik. Untuk konten dari website KEPO e-magazine juga dianggap sangat menarik, isi dar kontennya pun dianggap sangat mudah dipahami.Ketika ditanyakan mengenai Apakah pembaca mengalami kesulitan saat membuka website? Misalnya berkendala dengan fitur-fitur dalam website/ tidak bisa membuka konten/ sulit mengakses halaman website, ditemukan bahwa web KEPO e-magazine sangat mudah diakses. Dalam pembinaan e-magazine KEPO tahap pertama, juga diberikan materi mengenai media sosial dan bagaimana mengelolanya. Tim redaksi KEPO e-magazine membuat media sosial dalam bentuk Instagram. Tampilan dari Instagram KEPO e-magazine mendapat respon sangat baik dari pembaca. Terkait dengan media sosial, ditanyakan pada pembaca mengenai konten dari sosial media Instagram milik KEPO e-magazine yang diberi nama @kepoinipto, Sebagian besar pembaca menganggap konten nya sudah cukup menarik dan isi kontennya pun mudah dipahami.

Dari survey ditemukan secara keseluruhan baik website dan sosial media berupa instagram edisi pertama KEPO e-magazine mendapat respon sangat baik dari pembaca. Selain itu pembaca juga berharap KEPO e-magazine bisa rutin terbit setiap bulan. 


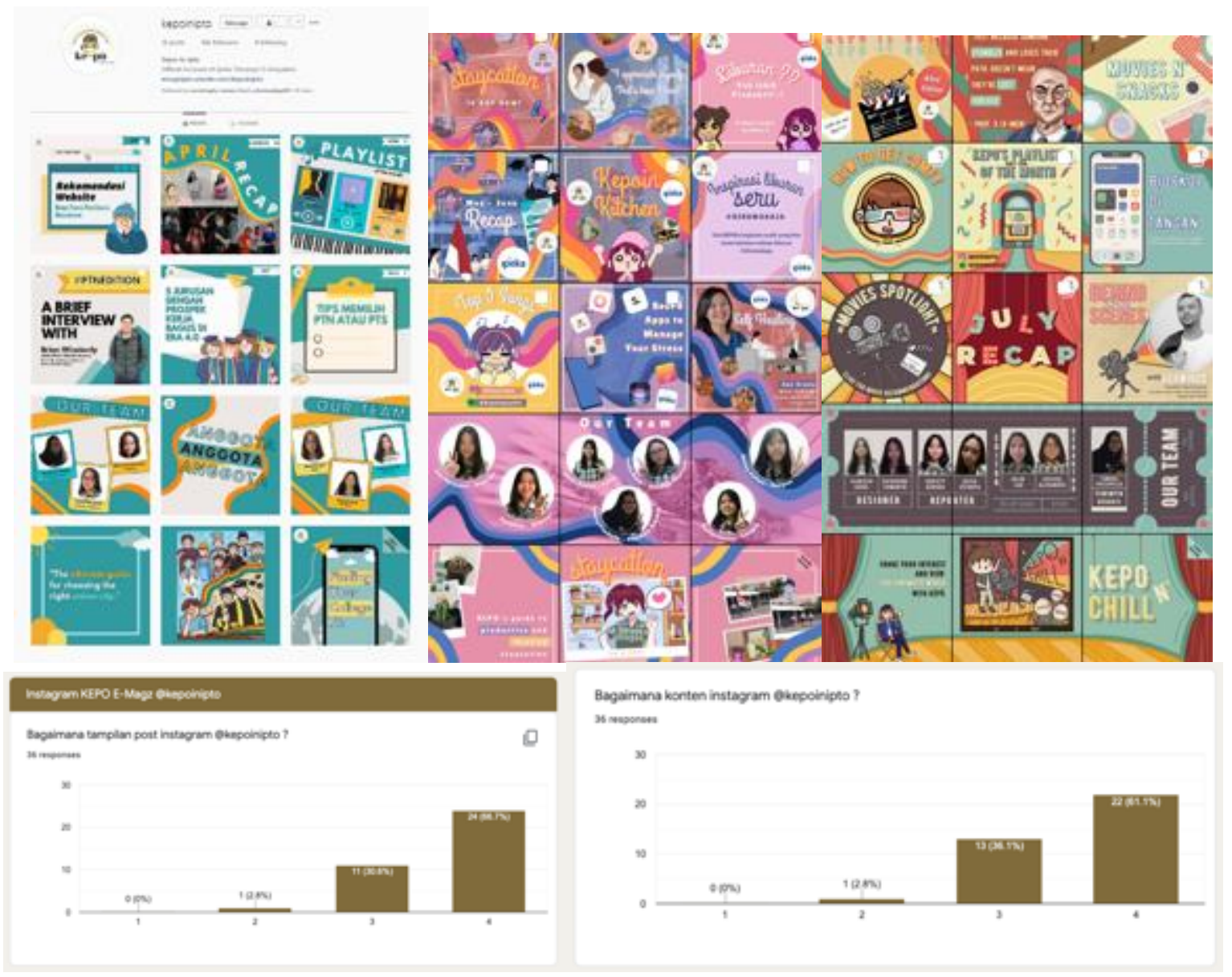

Gambar 3. Tampilan Konten Sosial Media Instagram KEPO e-magazine

Respon pembaca:

- Sangat baik dan terkagum karena ini pertama kalinya IPEKA mengeluarkan majalah, terlebih dalam bentuk e-magazine.

- Dari segi pengemasan sangat menarik ada yang di website dan instagram.

- Kontennya pun menarik dan sesuai dengan pembaca, terutama dengan tema perkuliahan.

- Beberapa pembaca juga memberikan ide untuk tema edisi selanjutnya

- Ditemukan saran untuk penggunaan warna yang lebih colorfull

- Ukuran dari font yang digunakan juga menjadi sorotan, pembaca menyarankan agar besar kecil dari font diperhatikan

- Selain itu juga mengenai layout yang masih agak berantakan, sehingga perlu diperhatikan urutannya

Evaluasi dari tim UNTAR:

Setelah dilakukan sejumlah pembinaan pengelolan majalah pada pengurus "kepoinipto" dalam review terakhir tim PKM UNTAR memberikan evaluasi berupa batasan dasar desain, seperti whitespace, hierarchy, alignment, contrast, dan sebagainya, juga mengenai konten editorial seperti jenis-jenis artikel, serta publikasi dan marketing.

Dalam segi desain diberikan beberapa evaluasi seperti dibawah ini

1. Pemilihan warna, ada beberapa desain yang warnanya kurang selaras dan warna tipografi yang terlalu mirip dengan background sehingga mengurangi tingkat legibility. 
2. Penggunaan font yang seharusnya hanya untuk headline dipakai menjadi body text sehingga mengurangi kejelasan hierarchy dalam desain.

3. Kurangnya whitespace yang mengakibatkan desain terkesan sangat penuh dan "menakutkan" untuk dibaca.

4. Continuity/kesinambungan seluruh feeds instagram juga perlu diperhatikan lagi.

5. Margin perlu disesuaikan dengan media yang digunakan, misalnya agar teks atau ilustrasi tidak tertimpa username dan kotak reply di instagram story, dsb.

Melalui evaluasi yang disampaikan ini semoga bisa diterapkan pada publikasi-publikasi selanjutnya sehingga dapat menjadi lebih baik lagi, namun publikasi 1-3 sudah cukup baik dan menarik.

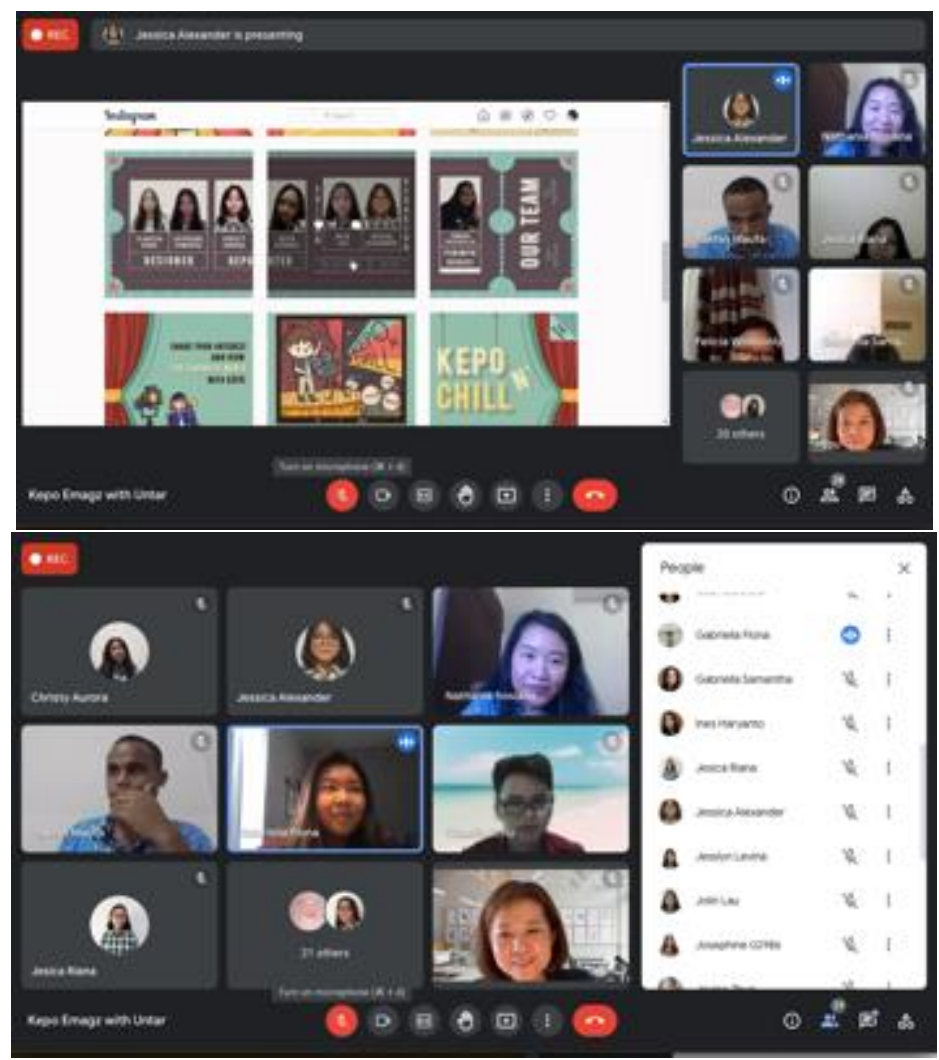

Gambar 4. Dokumentasi Pelaksanaan Evaluasi

Dalam konten terdapat beberapa hal yang perlu diperbaiki seperti:

1. Penulisan teks yang kurang konsisten (ada yang ditulis secara italic, ada yang tidak) dan kekurangtepatan tanda baca. Seharusnya penulis dan editor memeriksa dengan lebih teliti lagi tentang pemilihan kata, mana yang berasal dari Bahasa Indonesia atau Bahasa Inggris, mana yang seharusnya dicetak miring atau tidak. Penulisan tanda baca juga sebaiknya lebih diperhatikan, untuk kalimat mengajak atau bernada naik diakhiri dengan tanda seru sedangkan kalimat tanya diakhiri dengan tanda tanya.

2. Untuk meng-highlight teks pada artikel ada baiknya tidak menggunakan stabilo atau warna yang berbeda, tapi bisa menggunakan penulisan bold atau underline.

3. Ada beberapa artikel yang bagian intronya kurang mendalami topik, Mungkin hal ini bisa diatasi dengan mengurangi pembahasan topik yang secara umum dengan lebih difokuskan dan didalami pada topik yang diangkat. 
4. Ada beberapa pengulangan kata yang sedikit bertele-tele. Untuk memperbaiki hal ini, bisa lebih disesuaikan pemilihan katanya agar singkat, padat, dan jelas.

5. Layout dan alignment kurang konsisten. Lebih baiknya, ditetapkan dari awal, akan menggunakan layout dan alignment (rata paragraf) jenis apa sehingga salam sebuah artikel akan terlihat rapi dan nyaman ketika dibaca.

\section{KESIMPULAN DAN SARAN}

Secara keseluruhan setelah terbit sebanyak 3 edisi hasil dari KEPO e-magazine IPEKA telah lebih dari ekspektasi awal. Tim dari KEPO e-magazine IPEKA telah menghasilkan kualitas desain dan konten yang cukup baik, walaupun secara desain masih kurang menerapkan prinsip prinsip desain yang telah diberikan di awal serta beberapa bagian yang dinilai masih terlalu ramai. Hal ini masih sangat bisa dimaklumi karena tim tidak memiliki latar belakang desain. Dari segi konten tim KEPO e-magazine IPEKA dinilai sangat kreatif dan interaktif dengan selalu memberikan hal hal baru untuk para pembacanya.

\section{Ucapan Terima Kasih (Acknowledgement)}

Terima kasih kepada Ketua Lembaga Penelitian dan Pengabdian kepada Masyarakat Universitas Tarumanagara yang telah memberikan kesempatan untuk melakukan pengabdian ini, juga kepada Manager bidang PKM dan staff di LPPM Untar yang telah membantu dan mendukung, kepada Panitia Serina Universitas Tarumanagara. SMK IPEKA TOMANG, Jakarta, Bapak T. Setiawan Santoso selaku kepala sekolah, dan Ibu Nathania Hosiana yang telah memberikan kesempatan, informasi serta bantuan selama Seminar. Tim redaksi majalah SMK IPEKA TOMANG, Jakarta dan tim Redaksi ArtMax FSRD Untar: Claudio Schu Ferrario Primulya, Sherissa Bonifacia, Gabriella Fiona Fidelia yang telah ikut berpartisipasi.

\section{REFERENSI}

Arifiani, Faradina. 2013. Pengembangan Majalah Sekolah sebagai Media Pembelajaran Bahasa Indonesia di SMP. Laboratorium UM. SKRIPSI Jurusan Sastra Indonesia - Fakultas Sastra UM

Diyanti, Kadek Risma; Wendra, I Wayan \& Tantri, Ade Asih Susiari. (2021) Pembinaan Majalah Sekolah Gempita Esaba dan Relevansi Terhadap Bahan Ajar Bahasa Indonesia di SMP Negeri 1 Bangli. Jurnal Pendidikan Bahasa dan Sastra Indonesia, Vol 11, No 2, 250-259. http://dx.doi.org/10.23887/jjpbs.v11i2.36175

https://kbbi.web.id/majalah diakeses 10 Februari 2021

Nurasiah Hasanah, Program Literasi Sekolah dalam Meningkatkan Kedisiplinan Siswa SMA Negeri 8 Yogyakarta. Universitas Islam Negeri Sunan Kalijaga Yogyakarta, 2017.h.5.

Rustan, S. (2014). Layout Dasar dan Penerapannya. Jakarta: Gramedia.

Sutherland, R., \& Barb, K. (2004). Graphic Designer's Color Handbook. Rockpot Publisher.

Utami, Santi Pratiwi Tri \& Syaifudin, Ahmad. (2011) Pelatihan Penyuntingan Bahasa Sebagai Upaya Meningkatkan Kualitas Majalah Sekolah Pada Anggota Forum Majalah Sekolah Se-Surakarta (Formasta). Jurnal Abdimas, Vol 15, No.2, 88-95. https://journal.unnes.ac.id/nju/index.php/abdimas/article/view/9898/0

Valentina, Anny \& Chrissandy Rubby, Pembinaan Tata Kelola Desain Majalah Sebagai Upaya Membangun Majalah Sebagai Media Komunikasi Sekolah. Prosiding Seri Seminar Nasional (Serina) 2021, Universitas Tarumanagara Jakarta 